\title{
Comentario
}

\section{El usuario: ¿sujeto u objeto de estudio?}

C onocer es una necesidad humana que deviene de la curiosidad, la cual impele a buscar los elementos que la satisfagan, toda vez que está satisfecha se ha generado un cambio irreversible en un sujeto. Esta necesidad del sujeto de conocer y de comunicar lo conocido a otros conforma la sabiduría humana; importa en algún punto que aquello que se ha aprehendido sea socializado. Ahora bien, la satisfacción de una curiosidad nos lleva a la investigación, a actos como indagar y contemplar asombrados, registrar lo que nos asombró y hacerlo extensivo, es la intención natural comunicar lo hallado. En bibliotecología se han investigado diversos fenómenos entre los que sobresalen la organización de la información, el impacto de las tecnologías de información y comunicación en los procesos de organización, y la transferencia de información, entre otros, éstos suelen verse como parte de su objeto de estudio; surge entonces la pregunta, ¿el usuario es un sujeto o un objeto de estudio? ${ }^{1}$

La respuesta a la primera parte de la pregunta es clara, sí es un sujeto de estudio. Esta afirmación deriva de una búsqueda exhaustiva de la literatura sobre el tema, cuya finalidad fue identificar el uso del término como fenómeno de investigación, es decir como objeto de estudio: su esencia; sus características; qué elementos lo componen; el alcance que tiene y sus limitaciones. Se quería identificar la existencia o no de marcos o modelos teóricos que lo definieran puntualmente. Esta revisión nos permitió determinar que existe una gran cantidad de estudios sobre las

1 El objeto de estudio corresponde al término o forma del acto del conocimiento, es decir, aquello que es alcanzado primariamente mediante la razón, concretamente el campo de conocimiento de una ciencia o disciplina. 
características de los usuarios/sujetos de estudio: sus necesidades de información; su comportamiento en la búsqueda y recuperación; el uso que hace de la información; su actitud hacia las unidades y/o profesionales de la información; y su satisfacción; sin embargo la búsqueda arrojó sólo unos cuantos registros sobre lo que se buscaba: su esencia teórica.

Esta necesidad de encontrar la esencia de los subcampos fenoménicos se puede generalizar a todas las áreas de las disciplinas bibliotecología y ciencia de la información a nivel mundial, y más específicamente en América Latina. En esta región nos enfrentamos a los siguientes problemas epistemológicos: falta de dominio de referentes teóricos y de métodos, técnicas e instrumentos de investigación en general; y en particular cuando para abordar el tema usuarios existe la falta de aceptación de los conceptos generados al interior de la comunidad epistémica.

El tema usuarios se ha concebido desde una perspectiva práctica, básicamente relacionada con los estudios de usuarios, aunado a lo anterior resalta el hecho de que las pocas investigaciones teóricas que han generado conceptos desafortunadamente no se han retomado. Lo anterior puede deberse a dos causas principales: a que la bibliotecología ha sido considerada como una actividad profesional y no como una disciplina, con un campo teórico y metodológico establecido; y a que existen pocas investigaciones sobre aspectos teóricos en esta región.

Responder a la segunda parte de la pregunta ¿es un objeto de estudio? es un poco más difícil. Para muchos el tema usuarios debe permear todos los campos de la bibliotecología, por ejemplo en la organización para los usuarios o los usuarios y las tecnologías, el problema es qué hilo conductor se sigue para explicar los hallazgos, si ¿el de la organización, el de las tecnologías o el del usuario?

La base de una teoría es la argumentación, es decir la explicación de los fenómenos, la cual debe seguir un referente que la haga consistente, y por hilo conductor se entiende ese referente teórico que permite generar la argumentación de los resultados de las investigaciones: enfoque cognitivo, estructuralista, sistémico, entre otros. Una argumentación estructuralista de lo relacionado con los usuarios nos dará una visión diferente de una 8 basada en el enfoque cognitivo. 
Surge otro problema, ¿cómo abordar el fenómeno? ¿cómo transito para explicar; es decir, qué camino sigo, qué tendencia metodológica, qué método, qué técnica? Los resultados que se obtienen desde una perspectiva cuantitativa son diferentes a los obtenidos desde una cualitativa; una encuesta nos lleva a conclusiones descriptivas y generalistas, en cambio, el incidente crítico a otras de corte más específico y de interpretación.

Si el usuario es visto sólo como sujeto de estudio lo mismo da utilizar métodos cuantitativos que cualitativos, considerarlo como objeto nos exige ampliar la visión metodológica, y seguir métodos y técnicas que nos permitan un mayor acercamiento; no será más un sujeto que va a ser descrito, sino un objeto de estudio que será explicado y conformará el entramado teórico de la bibliotecología y de la ciencia de la información.

Tenemos pues, que pensar al usuario en singular y como objeto de estudio, además de percibirlo en plural y como sujeto de atención, resolverá los problemas epistemológicos de la disciplina, además de los prácticos de la profesión.

La creación de marcos conceptuales es un asunto que se inserta en la necesaria explicación de cualquier disciplina en consolidación, el desarrollo de proyectos sobre usuarios de esta índole requiere introducirse en la epistemología de la disciplina bibliotecológica y que se estudien a profundidad aspectos teóricos y metodológicos con el fin de crear y/o recrear un conocimiento que establezca, refuerce o cuestione sus bases o fundamentos teóricos.

Se debe enfatizar el carácter de objeto de estudio del fenómeno usuario de la información y no sólo tenerlo como sujeto de descripción, verlo así abonará en favor de la construcción de nuestras disciplinas para que en un futuro cercano, logremos consolidarlas. 